\title{
RESEARCH
}

Open Access

\section{Renal cancer-derived exosomes induce tumor immune tolerance by MDSCs- mediated antigen-specific immunosuppression}

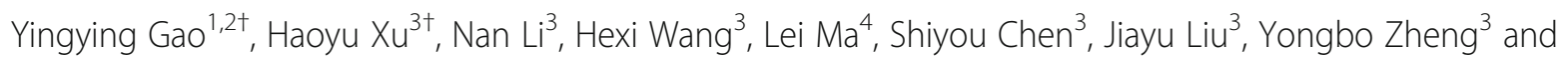
Yao Zhang ${ }^{3^{*}}$ (D)

\begin{abstract}
Backgound: Although Myeloid-derived suppressor cells (MDSCs) have a prominent ability to suppress the immune responses of T lymphocytes and propel tumor immune escape, a lack of profound systemic immunesuppression in tumor-bearing mice and tumor patients. The underlying mechanism of these remains unclear.

Methods: For this purpose, renal cancer-derived exosomes (RDEs) were first labeled with PKH67 and been observed the internalization by MDSCs. Flow cytometry analysis showed the proportion and activity change of MDSCs in spleen and bone marrow induced by RDEs. Further, western blot experiments were used to verify triggered mechanism of MDSCs by RDEs. Finally, proliferation and cytotoxicity of cytotoxic T lymphocytes (CTLs) cocultured with MDSCs in vitro and a series of experiments in vivo were performed to demonstrate the specific inhibitory effect of RDEs-induced MDSCs.

Results: This study suggested that RDEs crucially contributed to presenting antigenic information, activating and driving specific immunosuppressive effect to MDSCs. HSP70, which is highly expressed in RDEs, initiate this process in a toll like receptor 2 (TLR2)-dependent manner. Importantly, RDEs-induced MDSCs could exert an antigen-specific immunosuppression effect on CTL and specific promote renal tumors-growth and immune escape in consequence.

Conclusion: The immunosuppression mediated by MDSCs which is induced by RDEs is antigen-specific. HSP70, which is highly expressed in RDEs, plays a pivotal role in this process. Targeted abrogating the function of MDSCs, or eliminating the expression of HSP70 in exosomes, or blocking the crosstalk between them provides a new direction and theoretical support for future immunotherapy.
\end{abstract}

Keywords: RDEs, MDSCs, Antigen-specificity, Tumor immune escape, HSP70

\footnotetext{
*Correspondence: zhangyao7407@126.com

†Yingying Gao and Haoyu Xu contributed equally to this work.

${ }^{3}$ Department of Urology, The First Affiliated Hospital of Chongqing Medical

University, No. 1, medical college road, Yuzhong district, Chongqing 408000,

China

Full list of author information is available at the end of the article
}

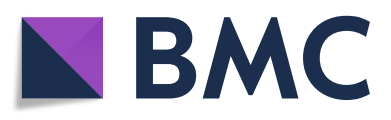

(- The Author(s). 2020 Open Access This article is licensed under a Creative Commons Attribution 4.0 International License, which permits use, sharing, adaptation, distribution and reproduction in any medium or format, as long as you give appropriate credit to the original author(s) and the source, provide a link to the Creative Commons licence, and indicate if changes were made. The images or other third party material in this article are included in the article's Creative Commons licence, unless indicated otherwise in a credit line to the material. If material is not included in the article's Creative Commons licence and your intended use is not permitted by statutory regulation or exceeds the permitted use, you will need to obtain permission directly from the copyright holder. To view a copy of this licence, visit http://creativecommons.org/licenses/by/4.0/. The Creative Commons Public Domain Dedication waiver (http://creativecommons.org/publicdomain/zero/1.0/) applies to the data made available in this article, unless otherwise stated in a credit line to the data. 


\section{Backgound}

In spite of generally recognized that the essential of tumorigenesis is a result of genomic alteration, discoveries made over the past decades have suggested that an altered crosstalk between the tumor microenviroment and the host immune system may also provide growth advantages to tumor cells [1,2]. Multiple studies have indicated that $\mathrm{T}$ lymphocyte anergic is one of the major mechanisms of tumor escape [3-5], however the mechanism is still ill certify.

Previous studies have reported that myeloid-derived suppressor cells (MDSCs) are a heterogeneous population of immature myeloid cells (IMCs) infiltrating the tumor microenvironment with potent tumor-associated $\mathrm{T}$ lymphocyte tolerance and immunosuppressive activity $[4,6,7]$. MDSCs are characterized by cell-surface markers

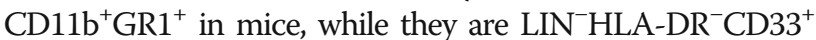
or $\mathrm{CD} 11 \mathrm{~b}^{+} \mathrm{CD} 14^{-} \mathrm{CD} 33^{+}$in humans. In healthy individuals, they are the precursors of dendritic cells (DCs), macrophages and granulocytes $[8,9]$, while a obvious expansion was observed in bone marrow (BM) or tumor tissues of tumorbearing mice or cancer patients [10-12]. However, in practice, tumor patients and tumor-bearing mice do not show systemic immunity dysfunction and can still have strong immune attack ability against other non-autoantigens.

Tumor cell-derived exosomes (TDEs) are multivesicular bodies and secreted by tumor cells, with diameters ranging from 30 to $100 \mathrm{~nm}$. Our previous researches showed a lot of basic research on renal cancer-derived exosomes (RDEs) $[13,14]$ and found that it carried a set of tumor-associated antigens, and immune modulation molecules such as G250, heat shock protein (HSP), tetraspanins, major histocompatibility complex molecules (MHC) I and II, adhesive molecule ICAM-1, et al. Recent study also showed TDEs dictated the amplification of MDSCs [15]. However, the triggered mechanisms of activation have not been fully addressed.

Myeloid differentiation primary-response gene 88 (MyD88), an important cytoplasmic adaptor molecule for integrating and transducing the signals triggered by all Toll-like receptors (TLRs) family except TLR3, has been reported inducing MDSC expansion in sepsis [16]. While HSP70, overexpressed in RDEs, is an important endogenous ligand of TLRs [17].

Based on these, this study clarified our speculation that the immunosuppression of $\mathrm{T}$ lymphocyte drove by MDSCs is antigen-specific nature. RDEs and embedded HSP70 is actually responsible for MDSCs amplification, activation and induce renal tumor immune escape through a comprehensive of studies in vivo and vitro. Importantly, our findings provide a new idea for immunnotherapy and find a new break for targeted therapy of renal cell carcinoma, which has scientific exploration and clinical application prospect.

\section{Materials and methods}

\section{Mice}

Six-to-eight-week-old BALB/c mice, weighing 16-22 g, were purchased from and house in the Animal Experimental Center of Chongqing Medical University (Chongqing, China). All mice were fed under pathogen-free conditions with laminar air flow. All experimental manipulations were approved by the Ethics Committee of The First Affiliated Hospital of Chongqing Medical University.

\section{Cell lines and culture}

The mouse renal adenocarcinoma cell line, RenCa, breast cancer cell line, $4 \mathrm{~T} 1$, and colon cancer cell line, CT26, were purchased from Shanghai Cell Bank. Cells were cultured in RPMI-1640 medium (Thermo Fisher Scientific, Inc. Waltham, MA, USA) with $10 \%$ fetal bovine serum (FBS) (Thermo Fisher Scientific, Inc.) and $1 \%$ penicillin and streptomycin (Beyotime Institute of Biotechnology, ShangHai, China) in $37^{\circ} \mathrm{C}$ incubator with $5 \% \mathrm{CO}_{2}$.

\section{Exosome isolation, identification}

RDEs were isolated from conditioned medium collected from RenCa cells with or without HSP70 knockdown. Several centrifugation and filtration steps were used as previously described [13]. The specific operation steps are as follows: Culture supernatants $(100 \mathrm{ml})$ were collected and sequentially centrifuged $\left(4^{\circ} \mathrm{C}\right)$ at $300 \times \mathrm{g}$ for $10 \mathrm{~min}, 800 \times \mathrm{g}$ for $30 \mathrm{~min}$ and $10,000 \times \mathrm{g}$ for $30 \mathrm{~min}$. The clarified supernatant was concentrated by centrifugation at $1000 \times \mathrm{g}$ for $30 \mathrm{~min}$ in a prerinsed $100 \mathrm{kDa} \mathrm{MWCO}$ Centrifugal Filter Device and the concentrated exosomes were collected and resuspended in $20 \mathrm{ml}$ PBS. The ultracentrifuge supernatant was underplayed with $30 \%$ sucrose $/ \mathrm{D}_{2} \mathrm{O}$ density cushion, followed by ultracentrifuging at $100,000 \times \mathrm{g}$ for $60 \mathrm{~min}$. At the bottom, the cushion was collected and diluted in $10 \mathrm{ml}$ of PBS. The exosomes were further concentrated by centrifuging for $30 \mathrm{~min}$ at $1000 \times \mathrm{g}$ inprerinsed $100 \mathrm{kDa}$ MWCO Amicon ultra-15 to a volume of about $3 \mathrm{ml}$. Membrane filter $(0.22 \mu \mathrm{m})$ was used, after sterilization the exosome was stored at $80^{\circ} \mathrm{C}$. After protein concentration was determined using BCA method (Beyotime Institute of Biotechnology), the morphological characteristics of RDEs were identified by transmission electron microscope (TEM) (JEM-2010, Jeol Ltd., Tokyo, Japan).

\section{Isolated MDSCs from spleen or BM and analyzed by flow cytometry}

Single-cell suspensions without erythrocyte were prepared from mice spleens or BM of BALB/c on different time point after treatment. $\mathrm{Gr}-1^{\text {high }} \mathrm{Ly}-6 \mathrm{G}^{+}$and $\mathrm{Gr}$ $1^{\mathrm{dim}} \mathrm{Ly}-6 \mathrm{G}^{-}$cells were respectively selected by being indirectly magnetically labeled with anti-Ly-6G-Biotin and 
anti-Biotin Microbeads (Miltenyi Biotech, Bergisch Gladbach, Germany) and anti-Gr-1-Biotin and Streptavidin Microbeads (Miltenyi Biotech). After the above two parts were collected together, MDSCs were stained with anti-Gr-1-FITC and anti-CD11b-PE antibodies (Biolegend, San Diego, CA, USA) and the proportions were analyzed by flow cytometry (Beckman Coulter, Pasadena, CA, USA). Then $10 \mathrm{ng} / \mathrm{ml}$ GM-CSF (PeproTech, Shanghai, China) and $2 \mathrm{ng} / \mathrm{ml} \mathrm{IL-6}$ (PeproTech) were supplemented to the medium and cultured at $37^{\circ} \mathrm{C}$ with $5 \% \mathrm{CO}_{2}$.

\section{Uptake of exosomes by MDSCs}

To perform uptake experiments, RDEs were labeled with PKH67 according to operating procedure (MINI67, Sigma-Aldrich, Merck KGaA, Darmstadt, Germany). Briefly, $200 \mu \mathrm{g}$ RDEs were resuspended in $2 \mathrm{ml}$ PBS with $4 \mu \mathrm{PKH} 67$ for $5 \mathrm{~min}$ in $37^{\circ} \mathrm{C}$. The final concentration of PKH67 is dye $2 \times 10^{-6} \mathrm{~mol} / \mathrm{L}$.

Next, $2 \mathrm{ml}$ 1\%BSA was added to terminate the staining for $1 \mathrm{~min}$, and the volume of the mixture was supplied to $20 \mathrm{ml}$ with $1 \%$ BSA. Then, the mixture was centrifuged at $120,000 \mathrm{~g}$ for $1 \mathrm{~h}$, repeatedly three times. The precipitation was the PKH67-labeled RDES. Twenty microgram of the PKH67-stained RDEs were cocultured with $2 \times 10^{5}$ MDSCs, and cells were harvested at $0 \mathrm{~h}, 6 \mathrm{~h}$ or $12 \mathrm{~h}$. At the same time, the $100 \mu \mathrm{g}$ of the PKH67-stained RDEs were injected intravenously to every mouse, and the splenetic MDSCs were extracted at $0 \mathrm{~h}, 24 \mathrm{~h}$ or $48 \mathrm{~h}$. All of these MDSCs were fixed, dyed nuclei and visualized with confocal microscopy.

\section{ROS detection, arginase activity and NO production}

The level of ROS production was measured using the oxidation-sensitive dye 2', 7'-dichlorodihydrofluorescein diacetate (DCFDA) (Thermo Fisher Scientific, Inc.). MDSCs were simultaneously incubated with $30 \mathrm{ng} / \mathrm{ml}$ Phrobol-12-myristate-13-acetate (PMA) (Sigma-Aldrich) and $4 \mu \mathrm{mol} / \mathrm{L}$ DCFDA for $30 \mathrm{~min}$ at $37^{\circ} \mathrm{C}$. Median Fluorescence Intensity (MFI) was used to mark the production of ROS in $535 \mathrm{~nm}$ by flow cytometry.

Arginase activity test using Arginase Activity Assay Kit (MAK112, Sigma-Aldrich) performed with the manufacturer's protocol.

To detect NO, Cell culture supernatant mixed with the same volume of Griess reagent for $10 \mathrm{~min}$ at $25^{\circ} \mathrm{C}$. Absorbance was measured at $550 \mathrm{~nm}$, and the concentrations of nitrite were calculated according to the standard curve.

\section{Western blot}

RenCa cells were transfected with HSP70 knockdown lentiviral particles and negative control (mock) (Shanghai GenePharma Co., Ltd., Shanghai, China). The expression of HSP70 in RDEs were checked by western blot. Then, MDSCs were co-cultured with RDEs ${ }^{\text {shRNA }}$ mock or $\mathrm{RDE}^{\mathrm{shHSP70}}$, or TLR-2 inhibitor $(\mathrm{C} 29,363,600-92-4$, $\mathrm{MCE})$. The protein extraction and Western blot analysis were performed as described previously [18]. The membranes were incubatedwith primary antibodies overnight at $4{ }^{\circ} \mathrm{C}$, then sequentiallyincubated with secondary antibodies for $2 \mathrm{~h}$ at room temperature. The intensity analyses were quantified using Image-Pro Plus 6.0 software. The primary antibodies and secondary antibodies incubated were as follows: The rabbit anti-mouse p38 (\#8690), p-p38 (\#4511), AP-1 (\#9164), Alix (\#92880), TLR-2 (\#13744), MyD88 (\#4283) were obtained from Cell Siganling Technology (CST). TSG101 (sc-7964), CD63 (sc-5275), GM130 (sc-55,590), TRAF6 (sc-8409) were obtained from Santa Cruz Biotechnoligy. HSP70 (ab181606), G250 (ab184006), horseradish peroxidase (HRP)-conjugated goat anti-rabbit secondary antibodies (ab6940), horseradish peroxidase (HRP)conjugated goat anti-mouse secondary antibodies (ab97040) were obtained from Abcam (Cambridge, MA, USA).

\section{Preparation of tumor cell lysates}

The tumor cell lysates were obtained from three types of tumor cell lines according to the previous methods [19]. By 5 cycles of freeze and thaw, Lysates were centrifugated at $800 \times \mathrm{g}$ for $30 \mathrm{~min}$, and the supernatants were filtered with a $0.22 \mu \mathrm{m}$ filter and stored at $-20^{\circ} \mathrm{C}$.

\section{Maturation of DCs pulsed by tumor cell lysates}

BM-derived DCs were isolated from mouse BM according to a previously described [20], with a certain modification. Erythrocyte-depleted mouse BM cells were cultured in complete medium supplemented with GMCSF $(10 \mathrm{ng} / \mathrm{ml})$ and IL-4 $(10 \mathrm{ng} / \mathrm{ml})$ (PeproTech, Rocky Hill, NJ). On day 7, tumor cell lysates were incubated with purified DCs at a ratio of 3:1. The phenotypic profile of DCs was detected by flow cytometry.

\section{Cytotoxic assays}

To confirm cytotoxic T lymphocytes (CTLs), the BMderived DCs, pulsed by tumor cell lysates, were injected subcutaneously into syngeneic mice. Unpulsed DCs and PBS were used as paralleled experimentations. As the protocol described previously [19], 14 days after injection, CD8+ T lymphocytes were sorted from mice splenocyte using CD8 microBeads (Miltenyi Biotech) [21]. Lactate dehydrogenase (LDH) release assay using CytoTox96 Non-Radioactive Cytotoxicity Assay Kit (Promega Biological Products, Ltd., Shanghai, China) was used to measure the cytolysis rate elicited by effector $\mathrm{T}$ lymphocytes against different tumor cells. Specific lysis (\%) was calculated based on the equation: (Experimental LDH release - effector cells - target spontaneous LDH release) / (target maximum LDH release) $\times 100$. 


\section{Inhibitory effect of MDSCs on CD8+ T lymphocytes proliferation}

$1 \times 10^{7}$ CTLs, derived from splenic CD8+ T lymphocytes stimulated by three different tumor cells lysates-pulsed DCs, were labeled with $2.5 \mu \mathrm{M}$ carboxyfluoresceindiacetate succinimidylester (CFSE, Macklin Biochemical Co., Ltd., Shanghai, China) at $25^{\circ} \mathrm{C}$ for $10 \mathrm{~min}$ in dark. Then different tumor cells antigen-stimulating CTLs were cocultured with MDSCs ${ }^{\mathrm{RDE}}$ or MDSCs ${ }^{\mathrm{PBS}}$ with a ratio of 5: 1 , PBS with same volume of were used as controls. After $24 \mathrm{~h}$, the proliferation of CTLs was analyzed by flow cytometry.

\section{Tumor growth assays}

Three different kinds of tumor model were established by subcutaneous injection with RenCa, $4 \mathrm{~T} 1$ or CT26 tumor cells $\left(3 \times 10^{6}\right.$ cell per mouse), respectively. Each tumor model was intravenously with MDSCs ${ }^{\mathrm{RED}}$ or MDSCs $^{\mathrm{PBS}}\left(1 \times 10^{6}\right.$ cells in $200 \mu \mathrm{l}$ PBS $)$ for 3 times a week. Same volume PBS was intravenously at the same interval as control group. The tumor size was assessed every 2 days. After 3 weeks, the mice were sacrificed by deep inhalation anesthesia (2-3\% isoflurane) and local analgesia (oxybuprocaine hydrochloride). Tumor tissues were isolated for comparing the size and performing histochemical experiments. Calculation of the formula $\mathrm{V}=\pi / 6 \times \mathrm{L} \times \mathrm{W}$ (L: length; W: width).

\section{Statistical analysis}

All data were reported as Mean \pm SD and repeated $\geq 3$ times independently. One-way analysis of variance (ANOVA) and two-way ANOVA were used evaluated the significant difference among groups using SPSS 21.0 (IBM Corp., Armonk, NY, USA) and GraphPad Prism software version 5 (GraphPad Software, Inc., La Jolla, CA, USA). A value of $P<0.05$ was considered as statistically difference.

\section{Results}

Tumor specific-antigen and HSP70 were enriched in RDEs

To test the feasibility of RDEs as a source of specificantigens for antitumor immunity in renal carcinoma, RDEs were first isolated from the serum free culture supernatants of RenCa cells. They exhibited spherical membrane-bound vesicles surrounded by the two-layer lipid membrane with a mean diameter of $50.1 \pm 23.2 \mathrm{~nm}$ and most diameters between 30 and $80 \mathrm{~nm}$ by TEM (Fig. 1a). The protein yield of RDEs were about 0.35$0.5 \mu \mathrm{g}$ per $1 \times 10^{6}$ tumor cells in $24 \mathrm{~h}$, as other tumor cells [22]. As expected, the RDEs sample was positive for exosomes biomarker proteins including transmembrane protein CD63, TSG101 and Alix [23], but negative for cir-Golgi marker GM130, which was only celluar protein (Fig. 1b). Further investigation revealed enriched renal carcinoma specific antigen G250 and immuno-modulators HSP70 was expressed in RDEs compared with their parental cells (Fig. 1c), which suggested that RDEs have the ability to present tumor specific-antigens and deliver antigen information to interacting target cells.

\section{RDEs carrying tumor antigens are captured by MDSCs}

In this study, immunomagnetic beads were used to isolate MDSCs and the flow cytometry verified the separation rate of positive cells were more than $90 \%$ (Fig. 1d). After cellular morphology was observed by microscope (Fig. 1e), immunofluorescence assay was used to identify the $\mathrm{Gr}-1$ and CD11b double-positive cells (Fig. 1f). This verified their validity to be used in the later functional experiments.

To examine whether RDEs can be uptake by MDSCs in vitro, the RDEs, labeled with PKH67, were cocultured with MDSCs (Fig. 1g). The internalization of PKH67-labelled RDEs by MDSCs was perinuclear and punctuate in appearance observed by fluorescence microscope at $6 \mathrm{~h}$ or $12 \mathrm{~h}$ (Fig. 1h). Next, to evaluate the ability of MDSCs to uptake RDEs in vivo, we isolated the splenic MDSCs at $24 \mathrm{~h}$ or $48 \mathrm{~h}$ after tail intravenously injected PKH67-labeled RDEs (Fig. 1i). Fluorescence signal was traced in these MDSCs using fluorescence microscope (Fig. 1j). Consistently, flow cytometry analysis showed an inceased fluorescence of MDSCs after the addition of PKH67-labeled RDEs in vitro, or after labeled RDEs were intravenously injected in vivo (Fig. $1 \mathrm{k}-\mathrm{l}$ ). The results revealed that the RDEs could be captured by MDSCs. In the same way, MDSCs might capture tumor antigen information.

\section{RDEs drived the expansion and activation of MDSCs}

To further examine whether exosome have ability to induce the expansion and activation of MDSCs, BALB/c mice model was intravenously injected RDEs $(10 \mu \mathrm{g}$ in $200 \mu \mathrm{l} /$ mouse $)$ or PBS $(200 \mu \mathrm{l} /$ mouse $)$ respectively three times per week for 30 days, and subcutaneously injected RenCa cells $\left(1.5 \times 10^{6} /\right.$ mouse $)$ as a positive control. After 7 days, Renca cells formed small transplanted tumors under the skin. Then spleen and BM cells were isolated at $10,20,30$ days respectively to examine the expansion of MDSCs (Fig. 2a). Flow cytometry analysis showed compared with control group treated with PBS, RDEs group and RenCa cells group showed significantly increased the expansion of $\mathrm{Gr}-1^{+} \mathrm{CD} 11 \mathrm{~b}^{+}$populations in $\mathrm{BM}$ cells at days 10 , and more obviously increased in days 20 and days 30 . Consistent results were obtained in spleen cells (Fig. 2b-e). Taken together, these results indicated that RDEs have the potential to induce MDSCs expansion in BM and spleen.

Historically, the activity of MDSCs in a pathological context is associated with the upregulated expression of immune suppressive factors such as arginase 1, and 


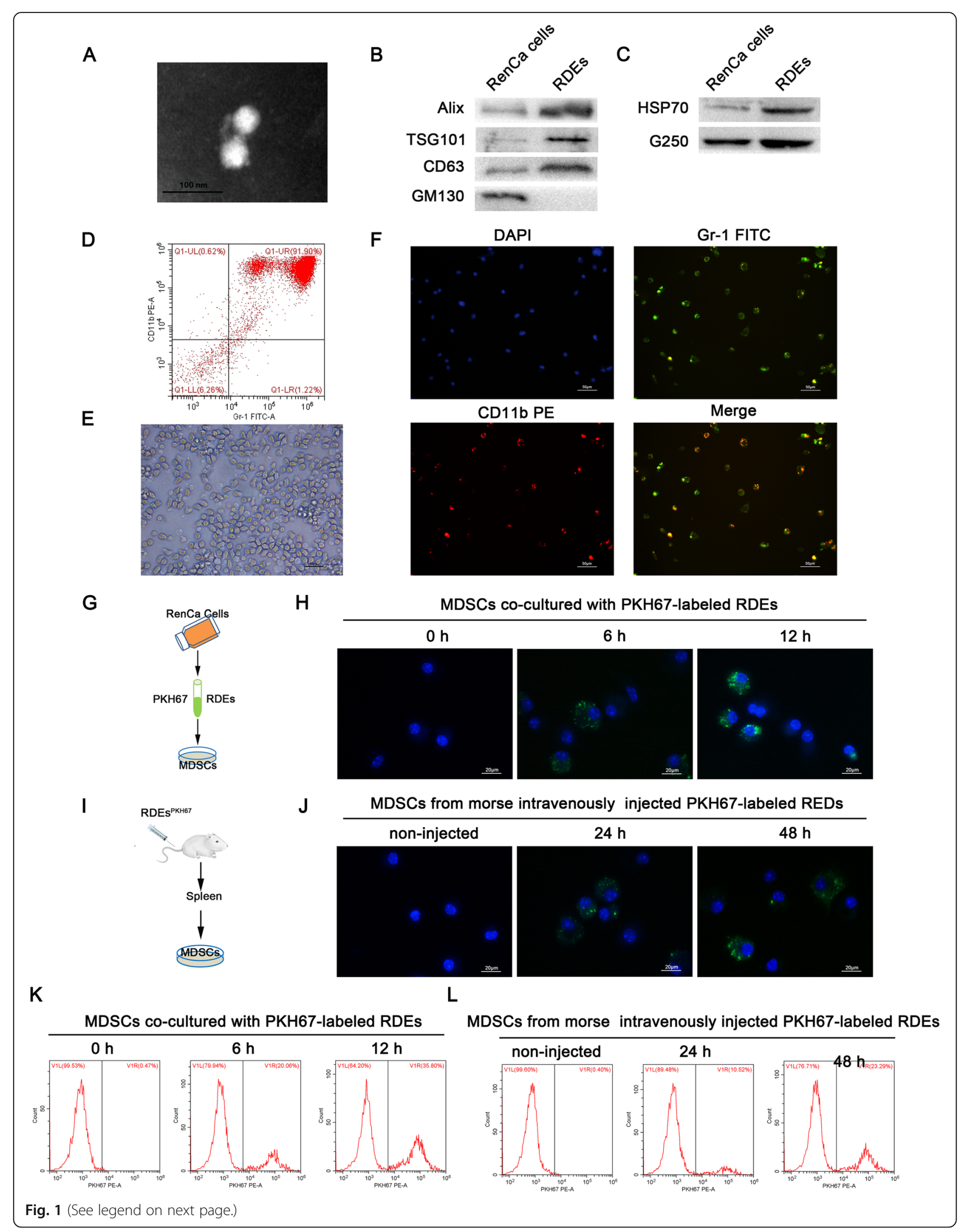


(See figure on previous page.)

Fig. 1 RDEs enriched with tumor specific-antigen and HSP70 could captured by MDSCs. a Typical morphologies and sizes of RDEs were identified by transmission electron microscopy (TEM). $\mathbf{b}$ Western blot was used for detecting the expression of exosomal biomarkers and cellular protein or c Renal-specific antigens (G250) and immuno-modulators (HSP70) in RenCa cell and RDEs. Thirty microgram of total protein was loaded for RenCa cell and RDEs, respectively. $\mathbf{d}$ The separation rate of MDSCs was verified by flow cytometry. The cellular morphology and characterization of MDSCs were observed by microscope (e) and immunofluorescence assay analysis (f). $\mathbf{g}$, i Schematic representation of the experiment in vitro and in vivo. $\mathbf{h}$ Representative phagocytosis of PKH67-labelled RDEs by MDSCs at $0 \mathrm{~h}, 6 \mathrm{~h}$ or $12 \mathrm{~h}$ in vitro. $\mathbf{j}$ Phagocytosis of RDEs by splenetic MDSCs in vivo at non-injected and $24 \mathrm{~h}$ or $48 \mathrm{~h}$ after intravenous injection with PKH67-labelled RDEs. The image was observed by confocal microscopy. Green, PKH67-labelled RDEs; Blue, DAPI. k Representative graph of fluorescence of MDSCs detected with flow cytometry as described in (h). I Representative graph of fluorescence of MDSCs from mouse spleen after tail intravenously injected PKH67-labeled RDEs as described in (j). All experiments were repeated at least three times and three mice were in each group

increased production of $\mathrm{NO}$, and reactive oxygen species (ROS) [4]. Thus, compared with MDSCs isolated from BM of PBS group, MDSCs induced from RDEs produced more ROS and NO and exhibited stronger arginase activity, just as these factors were activated in Rence cellsinduced MDSCs. The secretion of other factors which were involved in immunosuppressive functions, such as IL-10 and TGF- $\beta$, were also increased in RDEs-induced MDSCs group (Fig. 2f). The activity of MDSCs in spleen exhibited the similar results (Fig. 2g). These results suggested RDEs were involved in the induction of MDSCs amplification and activation. However, the inducing mechanism needs to be explored further.

\section{The activated of MDSCs induced by HSP70 expressed in RDEs}

To investigate whether HSP70 plays a significant role in activation of MDSCs, a series of HSP70 knockdown experiments were used in Renca cells. After the exosomes from Renca cells were isolated, HSP70 expression in RDEs were checked by western blot. ShHSP70\#2 markedly reduced the expression of HSP70 in RDEs and was used in later experiment (Fig. 3a). Subsequently, MDSCs were co-cultured with RDEs ${ }^{\text {shHSP70 }}$ or RDEs ${ }^{\text {shRNAmock }}$ in vitro. The results showed that RDEs could upregulate the expression of TLR2 and its downstream factors, such as MyD88, TRAF6, P38 and AP-1 in MDSCs (Fig. 3b). And with the induction of RDEs, MDSCs produced most ROS and NO and exhibited stronger arginase activity compared with the MDSCs primitive culture group (Fig. 3c). While, the expression of MyD88 and its downstream factors were blunted by HSP70 knockdown (Fig. 3b). Consistently, the activity of MDSCs is also significantly down-regulated (Fig. 3c).

In order to further characterize the activation mechanism of MDSCs, we treated the cells with TLR-2 inhibitor. The results showed that, TLR2 inhibitor can also reversed the expression level of factors in TLR/MyD88 signaling pathway (Fig. $3 \mathrm{~b}$ ) and the production of ROS and NO or arginase activity in MDSCs, which were upregulated by RDEs (Fig. 3d). Taken together, these results suggested that the proliferation and activation of
MDSCs were mediated via the binding of HSP70 in RDEs to TLR2 expressed on MDSCs.

\section{T lymphocytes immune responses were launched by the maturation of DCs}

DCs act as a bridge in the immune system. Matured DCs play a crucial role in capturing, processing and presenting tumor-specific antigens to $\mathrm{T}$ lymphocytes and initiate $\mathrm{T}$ lymphocyte proliferation and differentiation into helper and effector cells. To investigate these, we first stimulated DCs differentiation and maturation using freezingthawing tumor cells lysates. Compared with unpulsed group, tumor lysates of RenCa, 4 T1 and CT26 caused remarkable up-regulation of CD80, CD86 and MHC-II expression in DCs (Fig. 4a), which suggested the maturation of DCs could induced by tumor cells lystates.

To examine if matured DCs could drived T lymphocytes to trigger cytotoxicity against autologous tumor cells, CD8 + $\mathrm{T}$ lymphocytes acted as effector cells, extracted from the spleen of mice, were hatched with tumor cells lysates-pulsed DCs, unpulsed DCs or PBS (Fig. 4b), while autologous tumor cells acted as target cells. Coresponding E/T (effector/target) ratios were shown in Fig. 4c. The results suggested RenCa cell lysate-pulsed DCs stimulated CD $8+\mathrm{T}$ lymphocytes (CTLs $^{\text {RenCa }}$ ) displayed potent cytotoxic ability against RenCa cells at all E/T ratios compared with unpulsed DCs or PBS stimulated. Similar results can be observed at 4 T1 or CT26 cell lysate-pulsed DC-stimulated $\mathrm{CD} 8+\mathrm{T} \quad\left(\mathrm{CTLs}^{4 \mathrm{~T} 1}\right.$ or CTLs $\left.{ }^{\mathrm{CT} 26}\right)$. This indicates that matured DCs provokes $\mathrm{T}$ lymphocytes-dependent antitumor immunity.

\section{RDEs-induced MDSCs suppressed the cytotoxic effect of CD8 + T lymphocyte only on renal cancer cells}

To address our speculation that the immunosuppression effect of CTLs drived by RDEs-induced MDSCs is antigenspecific, CTLs obtained from the splenocytes of BALB/C mice stimulated by renal, breast or colon tumor cell lysates-pulsed DCs respectively. Three different sources of CTLs loaded with fluorescent dye CFSE were co-culture respectively with MDSCs induced by RDEs or not in vitro, PBS-treatment were used as negative controls (Fig. 5a).

Flow cytometry analysis showed MDSCs ${ }^{\mathrm{RDE}}$ could only significantly reduced the proliferation percentage of 


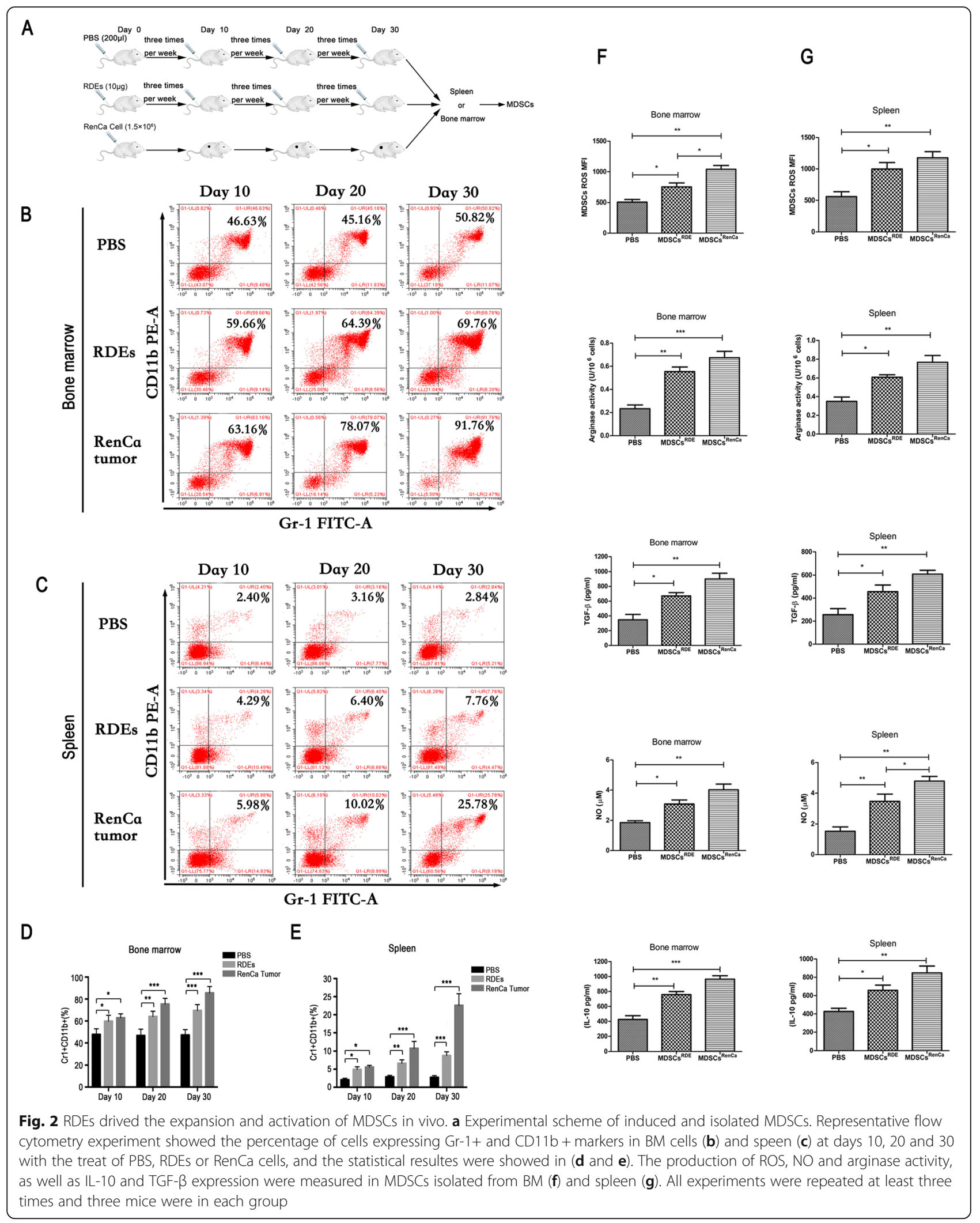




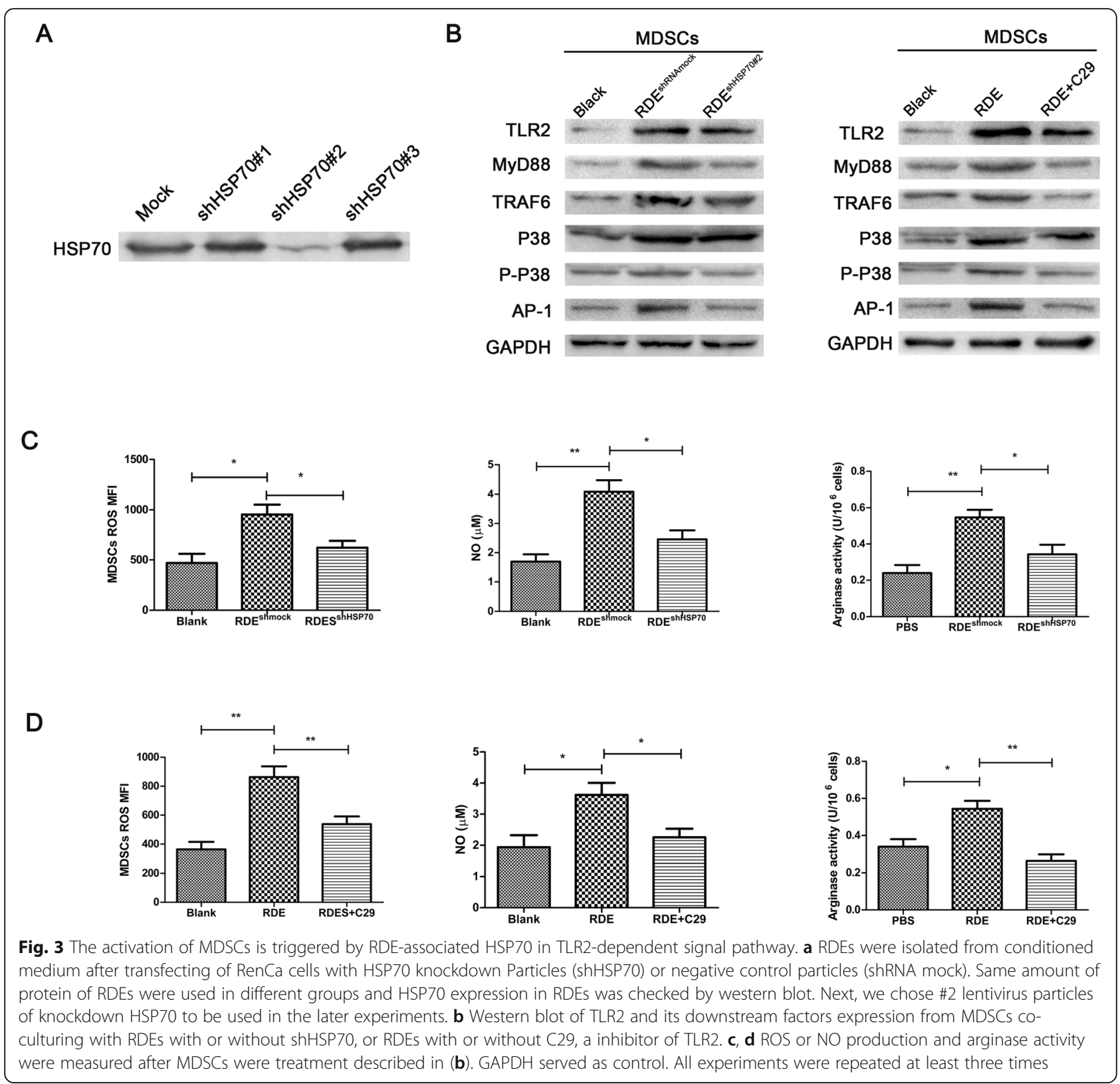

CTLs ${ }^{\text {RenCa }}$ compared with CTLs from other two sources, while there was no significant difference in the influence of $\mathrm{MDSCs}^{\mathrm{PBS}}$ or PBS (Fig. 5b, c). Consistently, MDSCs ${ }^{\mathrm{RDE}}$ could significantly inhibited cytotoxicity of CTL ${ }^{\text {RenCa }}$ compared with $\mathrm{MDSCs}^{\mathrm{PBS}}$ or PBS, but no obvious difference were observed on CTL ${ }^{4 T 1}$ and $\mathrm{CTL}^{\mathrm{CT} 26}$ (Fig. 5d). All the results indicated that TDEs-induced MDSCs exerted an obvious inhibitory effect on the proliferation and activation of CTLs, and the inhibitory effect is homologous specific.

\section{MDSCs activated by RDEs accelerated homeograft tumor} growth through immunosuppression of CTL

To further corroborate the antigen-specific immunosuppressive activity and tumor growth-promoting effect of
MDSCs in vivo, we established three different tumor models of BALB/c mice using Renca, 4T1and CT26 cells injected subcutaneously. Next, MDSCs ${ }^{\mathrm{PBS}}$ or MDSCs ${ }^{\mathrm{RDE}}$ was respectively injected intravenously in every tumor model, PBS was performed as negative control. The tumor size was measured at different time points. As the tumor microenvironment was consistent in all tumor models. Interestingly, supplementary MDSC ${ }^{\mathrm{RDE}}$ treatment significantly increased renal tumor growth compared to MDSC $^{\mathrm{PBS}}$-treated group (Fig. 6a-b). Consistently, a major increased in Ki67 positive cells were impacted by MDSCs $^{\mathrm{RDE}}$. But this significant difference in tumor growth and Ki67 positive cells between the MDSCs ${ }^{\mathrm{RDE}}$ groups and the MDSCs ${ }^{\mathrm{PBS}}$ groups was not observed in 4 


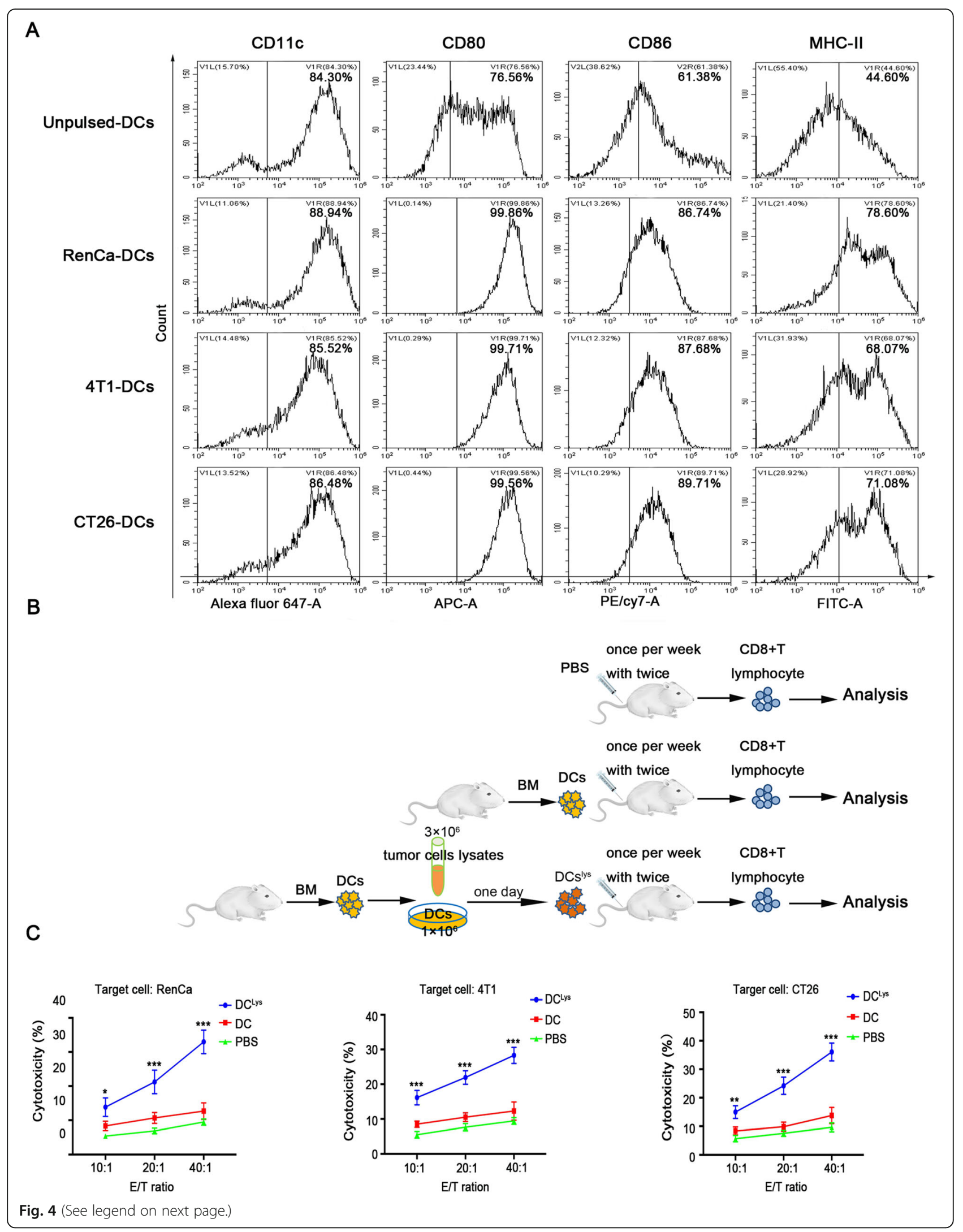


(See figure on previous page.)

Fig. $4 \mathrm{~T}$ lymphocytes cytotoxicity were launched by the maturation of DCs. a Flow cytometry for analyzing levels of surface proteins in DCs pulsed with RenCa cell lysate, 4T1 cell lysate, CT26 cell lysate or PBS (unpulsed control). b Experimental scheme was used for description the cytotoxicity of CD8 + T lymphocytes induced by DCs. c Cytolysis assay for CD8 + T lymphocytes activated by DCs ${ }^{\text {lys }}$ or DCs against autologous tumor cells at different E: T (effector: target) ratios. PBS was used as negative control. The data are representative of three independent experiments and expressed as the mean $\pm S D\left({ }^{*} P<0.05\right)$. DCs ${ }^{\text {lys }}$, the group of tumor cell lysate-pulsed DCs; DCs, the group of unpulsed DCs; PBS, the group of PBS-stimulated CD8 + T cells. All experiments were repeated at least three times and three mice were in each group

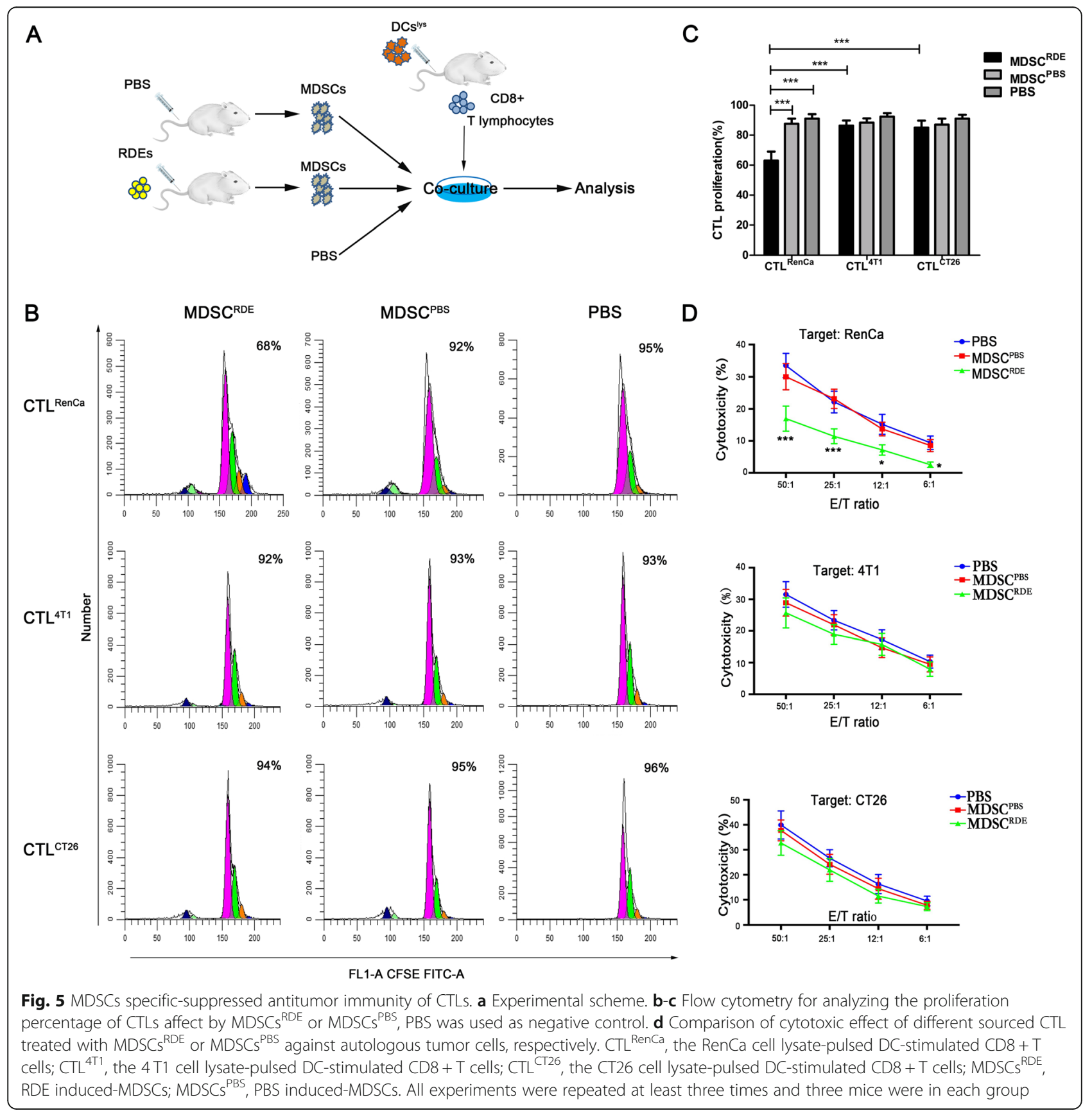




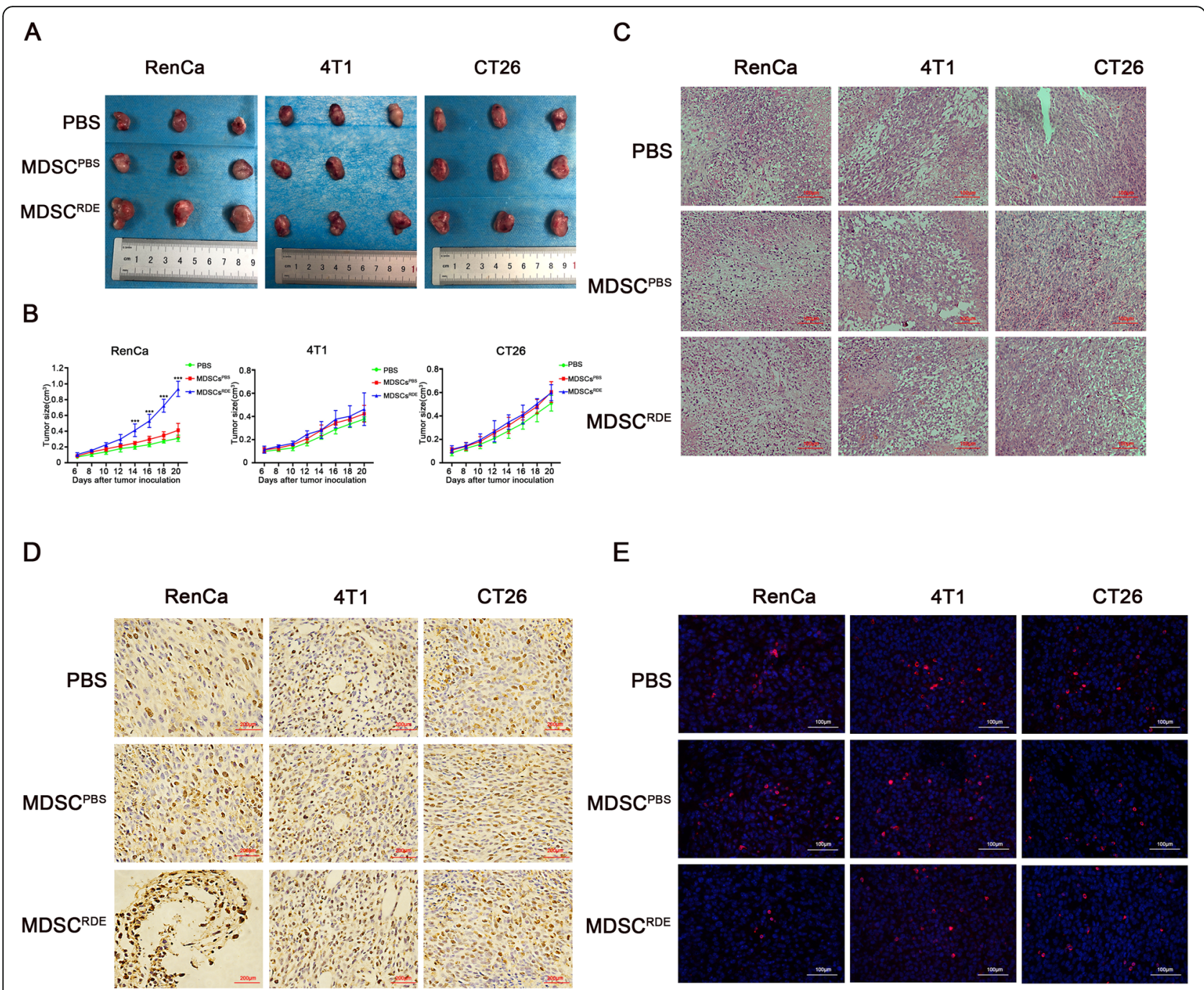

Fig. 6 MDSCs activated by RDEs accelerated homologous tumor growth through immunosuppression of CTL. Three different tumor models were established using BALB/C mice subcutaneously injected with Renca, 4T1 and CT26 cells. Each model was divided into three groups, treated with MDSCs ${ }^{R E D}, M D S C s^{P B S}$ or PBS, respectively. a The tumor was stripped and showed after the mice were sacrificed on days 20 after subcutaneous tumor cells. b Analysis and compare of tumor volume every 2 days in different treatment. c Representative haematoxylin and eosin (H\&E) staining of different group tumor model. d Representative Ki-67 immunohistochemical staining of different group (brown, Ki-67; blue, nuclei). e. CTLs infiltration in tumor tissues of various tumor models with different treatment by ISTS. Fluorescence images of tissue sections stained with CD8+ T in red and cell nuclei were labeled with DAPI (blue). All experiments were repeated at least three times and three mice were in each group

T1 or CT26 tumor-bearing mice (Fig. 6c-d). Next, In situ tetramer staining (ISTS) was used to show the presence of tumor-infiltrating CTLs in tumorbearing mice, which showed the amount of CTLs at tumor sites were significantly decreased in renal tumor model when mice were treated with MDSCs $^{R D E}$ compared to other tumor model (Fig. 6e). Taken together, these data supported the idea that MDSCs activated by TDEs can support the tumor growth through immunosuppression of CTL, but this growth promotion effect can only be targeted at homologous tumor.

\section{Discussion}

Defective $\mathrm{T}$ lymphocyte function induced by MDSCs represents one of critical factors in tumor progression $[24,25]$. In our study, a significant increase in MDSCs proportion and activation was observed in spleen and $\mathrm{BM}$ of tumor-bearing mice or normal mice following immunization with RDEs. Other studies also support our result. Accumulating evidences have shown, in different tumor model mice splenocytes, up to $20-40 \%$ of nucleated cells are MDSCs, while $2-4 \%$ in normal mice. MDSCs are also found in tumor tissues of tumorbearing mice or tumor patients peripheral blood $[9,26]$. 
However, the suppressive activity of MDSCs depend not only on the expansion of their proportion but also on the induction of their activation. RDEs, in our study, were also verified to increase the production of ROS, $\mathrm{NO}$ and strengthen the arginase activity in MDSCs. The direct role for these factors in the inhibition function of T lymphocyte is well established, although the immunosuppressive manner of MDSCs in these contexts is antigen-nonspecific. They could induct $\mathrm{T}$ lymphocyte apoptosis through blocking the activation of JAK3, STAT5 transcription factor, inhibiting the expression of MHC class II gene and $\zeta$-chain of CD3, or depleting Larginine which is an essential amino acid for T lymphocyte proliferation [27-31]. Therefore, $\mathrm{T}$ lymphocytes are anergy regardless of the specificity of the antigens these cells could encounter.

However, this statement seems less consistent with our results. In our study, we found that MDSCs activated by RDEs accelerated only homologous tumor growth and directly involved in the antigen-specific suppression of CTLs. Willimsky supported this view by statement that tumor-induced MDSCs did not inhibit CD8+ T lymphocyte responses to unrelated antigens in a model of sporadic cancer or other pathogens [32].

Addressing this paradox is based on that these mediators released by MDSCs are very short-lived substances and the function is transient, MDSCs may also suppress $\mathrm{T}$ lymphocytes by more stable and prolonged direct cellto-cell contact [33-35]. That means such contact could induce the antigen specific interaction between MDSCs and $\mathrm{T}$ lymphocytes. Of course, ROS and peroxynitrite are also necessary for mediating the factors expressed on the $\mathrm{T}$ lymphocytes which render the immunosuppressive to specific antigen. Notably, such medation neither leads to $\mathrm{T}$ lymphocyte death, nor prevents the immune response of $\mathrm{T}$ lymphocyte to nonspecific antigen.

Other evidence supporting this hypothesis is that MDSCs, acting as antigen-presenting cells, are able to capture tumor-associated antigens and some soluble factors, process and present them to $T$ lymphocytes [36, 37]. This is also be demonstrated in our study that RDEs which enrich with renal specific-antigen and HSP70 could be taken up by MDSCs and drive the activation and expansion of MDSCs. To our knowledge, it plays a crucial role in the antigen-specific tumor immune escape.

Next, Goc et al. reported that mature DCs initiate antigen-specific immunity, resulting in $\mathrm{T}$ lymphocyte proliferation and differentiation into helper and effector cells [38]. Our study also showed DCs can be matured using tumor cells lysates and in further trigger CTLs cytotoxicity against autologous tumor cells. DCs are part of normal differentiation from MDSCs. In pathological conditions, such as infections, trauma, sepsis, transpkantation, cancer or some autoimmune diseases, the differentiation of IMCs into mature myeloid cells, such as DCs or macrophages, were partially blocked, resulting in the expansion of MDSCs [39]. Therefore, antigenspecific $\mathrm{T}$ lymphocyte immunity may be restricted by this reason in the context of tumor microenvironment.

The antigen-specific immunosuppression induced by MDSCs helps to explain that T lymphocytes in lymphoid organs of tumor-bearing mice or blood of tumor patients can still respond to the stimuli of non-tumor-associated antigens, such as viruses, co-stimulatory molecules, IL-2, CD3 -/CD28- specific antibodies [37, 40-42]. Selective removing MDSCs may restores $\mathrm{T}$ lymphocytes immunotherapy against tumor, however, targeting of MDSCs is a technical challenge in clinical approaches at present. Here, we investigate potential targets for inducing MDSCs activation.

Although it was demonstrated that RDEs are involved in MDSCs expansion and activation, to date there is also no tool available to prevent exosomes releasing. Mechanistivslly, Both our results and data from another group support the idea that TLRs have a central role in mediating the activation of MDSCs [43], and the activation of MDSCs depended on TLR2/MyD88 pathways. These results suggest that the activation of MDSCs is a fundamental result of the innate response to pathogens expressing TLRs ligand. HSP70 deficiency in RDEs could be an attractive target for inhibiting the activity of MDSCs and tumor progression.

The main limitation of our study is the lack of patients analyzed. Besides, further studies need to determine whether the presence of HSP70 in exosomes could be served as an ideal non-invasive bio-marker for cancer diagnosis and guidance in medication.

\section{Conclusions}

In summary, our study described that MDSCs is a major factor of immune-escape in renal cancer, and the driver of the immunosuppression is antigen-specific. HSP70 enriched in RDEs plays a pivotal role in this process. Unlike previous research most focusing on re-activating the function of $\mathrm{T}$ lymphocytes against tumor cells characterized by DNA repair defects and higher neo-antigen loads with increased $\mathrm{T}$ lymphocyte infiltration [44, 45], our study described a novel immunotherapeutic strategy. Targeting blockade of either MDSC activity or the direct inhibition of HSP70 can be effective therapeutic strategies and deserve to be clinically evaluated. Once this immunotherapeutic strategy combined with established anticancer treatments, it is highly likely to improve treatment outcome of renal cancers.

\section{Abbreviations}

MDSCs: Myeloid-derived suppressor cells; RDEs: Renal cancer-derived exosomes; TLR2: Toll like receptor 2; TME: Tumor microenvironment; IMC: Immature myeloid cells; DCs: Dendritic cells; BM: Bone marrow; TDEs: Tumor cell-derived exosomes; HSP: Heat shock protein; MHC: Major 
histocompatibility complex molecules; MyD88: Myeloid differentiation primary-response gene 88; TLRs: Toll-like receptors; TEM: Transmission electron microscope; DCFDA: 2',7'-dichlorodihydrofluorescein diacetate; CTLs: Cytotoxic T lymphocytes; CFSE: Carboxyfluoresceindiacetate; PMA: Phrobol-12-myristate-13-acetate; MFI: Median Fluorescence Intensity; LDH: Lactate Dehydrogenase

\section{Acknowledgements}

The authors would like to thank Molecular oncology laboratory, The University of Chicago, America, for providing technical assistance.

\section{Authors' contributions}

YG and HX designed the experiments. HX and NL collected the specimens and analyzed the clinical data. HX, HW, SC, YZ and YL carried out the experiments. YG wrote the manuscript. YZ provided technical support of this research project and supervised the progress of the experiments. $Y G, H X$ and LM analyzed statistical data. YG and HX assembled and installed the figures. * contributed equally to this work. All authors have read and approved the final manuscript.

\section{Funding}

This work was supported by grants from the National Natural Science Foundation of China (NO. 81272572).

\section{Availability of data and materials}

The datasets supporting the conclusions of this article are included within the article and its additional files.

\section{Ethics approval and consent to participate}

This study was approved by the Ethics Committee of The First Affiliated Hospital of Chongqing Medical University. Animal experiments were done in accordance with the guidelines for the use of laboratory animals of the Chongqing Medical University Institutional Animal Care and Use Committee.

\section{Consent for publication}

Not applicable.

\section{Competing interests}

The authors declare no competing financial interests.

\section{Author details}

'Department of Laboratory Diagnosis, Chongqing Medical University, Chongqing 408000, China. ²Department of Laboratory Diagnosis, Jiamusi University, Jiamusi 154000, Heilongjiang, China. ${ }^{3}$ Department of Urology, The First Affiliated Hospital of Chongqing Medical University, No. 1, medical college road, Yuzhong district, Chongqing 408000, China. ${ }^{4}$ Department of Laboratory Diagnosis, The First Affiliated Hospital of Jiamusi University, Jiamusi 154000, Heilongjiang, China.

\section{Received: 12 March 2020 Accepted: 8 June 2020}

\section{Published online: 08 July 2020}

\section{References}

1. Schreiber RD, Old LJ, Smyth MJ. Cancer immunoediting: integrating immunity's roles in cancer suppression and promotion. Science. 2011;331: 1565-70.

2. Dunn GP, Old $\sqcup$, Schreiber RD. The immunobiology of cancer immunosurveillance and immunoediting. Immunity. 2004;21:137-48.

3. Williams JB, Horton BL, Zheng Y, Duan Y, Powell JD, Gajewski TF. The EGR2 targets $L A G-3$ and 4-1BB describe and regulate dysfunctional antigenspecific CD8+ T cells in the tumor microenvironment. J Exp Med. 2017;214: $381-400$.

4. Gabrilovich DI, Nagaraj S. Myeloid-derived suppressor cells as regulators of the immune system. Nat Rev Immunol. 2009;9:162-74.

5. Marigo I, Dolcetti L, Serafini P, Zanovello P, Bronte V. Tumor-induced tolerance and immune suppression by myeloid derived suppressor cells. Immunol Rev. 2008:222:162-79.

6. Mao FY, Zhao YL, Lv YP, Teng YS, Kong H, Liu YG, Wu XL, Hao CJ, Chen W, Duan MB, Han B, Ma Q, Wang TT, Peng LS, Zhang JY, Cheng P, Su CY, Fu XL, Zou QM, Guo G, Guo XL, Zhuang Y. CD45(+)CD33(low)CD11b(dim) myeloid-derived suppressor cells suppress CD8(+) T cell activity via the IL-6/ IL-8-arginase I axis in human gastric cancer. Cell Death Dis. 2018:9:763.

7. Adah D, Yang Y, Liu Q, Gadidasu K, Tao Z, Yu S, Dai L, Li X, Zhao S, Qin L, Qin $L$, Chen $X$. Plasmodium infection inhibits the expansion and activation of MDSCs and Tregs in the tumor microenvironment in a murine Lewis lung cancer model. Cell Commun Signal. 2019;17:32.

8. Veglia F, Perego M, Gabrilovich D. Myeloid-derived suppressor cells coming of age. Nat Immunol. 2018;19:108-19.

9. Kusmartsev S, Gabrilovich DI. Role of immature myeloid cells in mechanisms of immune evasion in cancer. Cancer Immunol Immunother. 2006;55:23745.

10. Gabrilovich DI. Myeloid-Derived Suppressor Cells. Cancer Immunol Res. 2017:5:3-8.

11. Diaz-Montero CM, Salem ML, Nishimura MI, Garrett-Mayer E, Cole DJ, Montero AJ. Increased circulating myeloid-derived suppressor cells correlate with clinical cancer stage, metastatic tumor burden, and doxorubicincyclophosphamide chemotherapy. Cancer Immunol Immunother. 2009;58: 49-59.

12. Diaz-Montero CM, Finke J, Montero AJ. Myeloid-derived suppressor cells in cancer: therapeutic, predictive, and prognostic implications. Semin Oncol. 2014;41:174-84.

13. Zhang Y, Luo CL, He BC, Zhang JM, Cheng G, Wu XH. Exosomes derived from IL-12-anchored renal cancer cells increase induction of specific antitumor response in vitro: a novel vaccine for renal cell carcinoma. Int J Oncol. 2010;36:133-40.

14. Zhang Y, Wu XH, Luo CL, Zhang JM, He BC, Chen G. Interleukin-12anchored exosomes increase cytotoxicity of $\mathrm{T}$ lymphocytes by reversing the JAKSSTAT pathway impaired by tumor-derived exosomes. Int J Mol Med. 2010;25:695-700.

15. Gobbo J, Marcion G, Cordonnier M, Dias AMM, Pernet N, Hammann A, Richaud S, Mjahed H, Isambert N, Clausse V, Rebe C, Bertaut A, Goussot V, Lirussi F, Ghiringhelli F, de Thonel A, Fumoleau P, Seigneuric R, Garrido C. Restoring anticancer immune response by targeting tumor-derived Exosomes with a HSP70 peptide Aptamer. J Natl Cancer Inst. 2016:108:1-11.

16. Delano MJ, Scumpia PO, Weinstein JS, Coco D, Nagaraj S, Kelly-Scumpia KM, O'Malley KA, Wynn JL, Antonenko S, Al-Quran SZ, Swan R, Chung CS, Atkinson MA, Ramphal R, Gabrilovich DI, Reeves WH, Ayala A, Phillips J, Laface D, Heyworth PG, Clare-Salzler M, Moldawer LL. MyD88-dependent expansion of an immature GR-1(+)CD11b(+) population induces T cell suppression and Th2 polarization in sepsis. J Exp Med. 2007;204:1463-74.

17. Diao J, Yang X, Song X, Chen S, He Y, Wang Q, Chen G, Luo C, Wu X, Zhang Y. Exosomal Hsp70 mediates immunosuppressive activity of the myeloid-derived suppressor cells via phosphorylation of Stat3. Med Oncol. 2015;32:453.

18. Gao Y, Li L, Li T, Ma L, Yuan M, Sun W, Cheng HL, Niu L, Du Z, Quan Z, Fan Y, Fan J, Luo C, Wu X. Simvastatin delays castrationresistant prostate cancer metastasis and androgen receptor antagonist resistance by regulating the expression of caveolin 1. Int J Oncol. 2019;54:2054-68.

19. Kim CH, Hong MJ, Park SD, Kim CK, Park MY, Sohn HJ, Cho HI, Kim TG, Hong YK. Enhancement of anti-tumor immunity specific to murine glioma by vaccination with tumor cell lysate-pulsed dendritic cells engineered to produce interleukin-12. Cancer Immunol Immunother. 2006;55:1309-19.

20. Koo JE, Shin SW, Um SH, Lee JY. X-shaped DNA potentiates therapeutic efficacy in colitis-associated colon cancer through dual activation of TLR9 and inflammasomes. Mol Cancer. 2015;14:104.

21. Baldan V, Griffiths R, Hawkins RE, Gilham DE. Efficient and reproducible generation of tumour-infiltrating lymphocytes for renal cell carcinoma. $\mathrm{Br}$ J Cancer. 2015:112:1510-8

22. Wolfers J, Lozier A, Raposo G, Regnault A, Thery C, Masurier C, Flament C, Pouzieux S, Faure F, Tursz T, Angevin E, Amigorena S, Zitvogel L. Tumorderived exosomes are a source of shared tumor rejection antigens for CTL cross-priming. Nat Med. 2001;7:297-303

23. Alvarez-Erviti $L$, Seow $Y$, Yin $H$, Betts C, Lakhal S, Wood MJ. Delivery of siRNA to the mouse brain by systemic injection of targeted exosomes. Nat Biotechnol. 2011:29:341-5.

24. Hwang WL, Lan HY, Cheng WC, Huang SC, Yang MH. Tumor stem-like cellderived exosomal RNAs prime neutrophils for facilitating tumorigenesis of colon cancer. J Hematol Oncol. 2019;12:10.

25. Liu JF, Ma SR, Mao L, Bu LL, Yu GT, Li YC, Huang CF, Deng WW, Kulkarni AB, Zhang WF, Sun ZJ. T-cell immunoglobulin mucin 3 blockade drives an antitumor immune response in head and neck cancer. Mol Oncol. 2017;11: 235-47. 
26. Serafini P, Borrello I, Bronte V. Myeloid suppressor cells in cancer: recruitment, phenotype, properties, and mechanisms of immune suppression. Semin Cancer Biol. 2006;16:53-65.

27. Long AH, Highfill SL, Cui Y, Smith JP, Walker A, Ramakrishna S, El-Etriby R, Galli S, Tsokos MG, Orentas R, Mackall CL. Reduction of MDSCs with all-trans retinoic acid improves CAR therapy efficacy for sarcomas. Cancer Immunol Res. 2016;4:869-80.

28. Bian Z, Abdelaal AM, Shi L, Liang H, Xiong L, Kidder K, Venkataramani M, Culpepper C, Zen K, Liu Y. Arginase-1 is neither constitutively expressed in nor required for myeloid-derived suppressor cell-mediated inhibition of Tcell proliferation. Eur J Immunol. 2018;48:1046-58.

29. Guha P, Gardell J, Darpolor J, Cunetta M, Lima M, Miller G, Espat NJ, Junghans RP, Katz SC. STAT3 inhibition induces Bax-dependent apoptosis in liver tumor myeloid-derived suppressor cells. Oncogene. 2019;38:533-48.

30. Nagaraj S, Nelson A, Youn Jl, Cheng P, Quiceno D, Gabrilovich DI. Antigenspecific CD4(+) T cells regulate function of myeloid-derived suppressor cells in cancer via retrograde MHC class II signaling. Cancer Res. 2012;72:928-38.

31. Chou HS, Hsieh CC, Yang HR, Wang L, Arakawa Y, Brown K, Wu Q, Lin F, Peters M, Fung JJ, Lu L, Qian S. Hepatic stellate cells regulate immune response by way of induction of myeloid suppressor cells in mice. Hepatology. 2011;53:1007-19.

32. Willimsky G, Czeh M, Loddenkemper C, Gellermann J, Schmidt K, Wust P, Stein $\mathrm{H}$, Blankenstein T. Immunogenicity of premalignant lesions is the primary cause of general cytotoxic T lymphocyte unresponsiveness. J Exp Med. 2008:205:1687-700.

33. Solito $S$, Bronte $V$, Mandruzzato $S$. Antigen specificity of immune suppression by myeloid-derived suppressor cells. J Leukoc Biol. 2011;90:31-6.

34. Lacotte S, Slits F, Orci LA, Meyer J, Oldani G, Delaune V, Gonelle-Gispert C, Morel $\mathrm{P}$, Toso C. Impact of myeloid-derived suppressor cell on Kupffer cells from mouse livers with hepatocellular carcinoma. Oncoimmunology. 2016;5:e1234565.

35. Nagaraj S, Gabrilovich DI. Tumor escape mechanism governed by myeloidderived suppressor cells. Cancer Res. 2008;68:2561-3.

36. Movahedi K, Guilliams M, Van den Bossche J, Van den Bergh R, Gysemans C, Beschin A, De Baetselier P, Van Ginderachter JA. Identification of discrete tumor-induced myeloid-derived suppressor cell subpopulations with distinct T cell-suppressive activity. Blood. 2008;111:4233-44.

37. Nagaraj S, Gupta K, Pisarev V, Kinarsky L, Sherman S, Kang L, Herber DL, Schneck J, Gabrilovich DI. Altered recognition of antigen is a mechanism of CD8+ T cell tolerance in cancer. Nat Med. 2007;13:828-35.

38. Goc J, Germain C, Vo-Bourgais TK, Lupo A, Klein C, Knockaert S, de Chaisemartin L, Ouakrim H, Becht E, Alifano M, Validire P, Remark R, Hammond SA, Cremer I, Damotte D, Fridman WH, Sautes-Fridman C, DieuNosjean MC. Dendritic cells in tumor-associated tertiary lymphoid structures signal a Th1 cytotoxic immune contexture and license the positive prognostic value of infiltrating CD8+ T cells. Cancer Res. 2014;74:705-15.

39. Varikuti S, Singh B, Volpedo G, Ahirwar DK, Jha BK, Saljoughian N, Viana AG, Verma C, Hamza O, Halsey G, Holcomb EA, Maryala RJ, Oghumu S, Ganju RK, Satoskar AR. Ibrutinib treatment inhibits breast cancer progression and metastasis by inducing conversion of myeloid-derived suppressor cells to dendritic cells. Br J Cancer. 2020;122:1005-13.

40. Mirza N, Fishman M, Fricke I, Dunn M, Neuger AM, Frost TJ, Lush RM, Antonia S, Gabrilovich DI. All-trans-retinoic acid improves differentiation of myeloid cells and immune response in cancer patients. Cancer Res. 2006;66:9299-307.

41. Monu N, Frey AB. Suppression of proximal T cell receptor signaling and lytic function in CD8+ tumor-infiltrating T cells. Cancer Res. 2007:67:11447-54.

42. Fricke I, Mirza N, Dupont J, Lockhart C, Jackson A, Lee JH, Sosman JA, Gabrilovich DI. Vascular endothelial growth factor-trap overcomes defects in dendritic cell differentiation but does not improve antigen-specific immune responses. Clin Cancer Res. 2007;13:4840-8.

43. Fleming V, Hu X, Weller C, Weber R, Groth C, Riester Z, Huser L, Sun Q Nagibin V, Kirschning C, Bronte V, Utikal J, Altevogt P, Umansky V. Melanoma extracellular vesicles generate immunosuppressive myeloid cells by Upregulating PD-L1 via TLR4 signaling. Cancer Res. 2019;79:4715-28.

44. Chen DS, Mellman I. Elements of cancer immunity and the cancer-immune set point. Nature. 2017;541:321-30.

45. Graff JN, Alumkal JJ, Drake CG, Thomas GV, Redmond WL, Farhad M, Cetnar JP, Ey FS, Bergan RC, Slottke R, Beer TM. Early evidence of anti-PD-1 activity in enzalutamide-resistant prostate cancer. Oncotarget. 2016;7:52810-7.

\section{Publisher's Note}

Springer Nature remains neutral with regard to jurisdictional claims in published maps and institutional affiliations.

Ready to submit your research? Choose BMC and benefit from:

- fast, convenient online submission

- thorough peer review by experienced researchers in your field

- rapid publication on acceptance

- support for research data, including large and complex data types

- gold Open Access which fosters wider collaboration and increased citations

- maximum visibility for your research: over $100 \mathrm{M}$ website views per year

At BMC, research is always in progress.

Learn more biomedcentral.com/submissions 